\title{
A AFIRMAÇÃO DO PRINCÍPIO DA PROTEÇÃO Á DIGNIDADE HUMANA COMO COMPONENTE DA ORDEM PÚBLICA
}

\author{
MAREN GUIMARÃES TABORDA*
}

"Vi tanta cruez! Pena não paga contar; se vou, não esbarro. E me desgosta, três que me enjoa, isso tudo. Me apraz é que o pessoal, hoje em dia, é bom de coração. Isto é, bom no trivial. Malícias maluqueiras, e perversidades, sempre tem alguma, mas escasseadas. Geração minha, verdadeira, ainda não eram assim. Ah, vai vir um tempo, em que não se usa mais matar gente.... Eu, já estou velho."

(João Guimarães Rosa, O Grande Sertão: Veredas)

\begin{abstract}
RESUMO: O artigo analisa um acórdão do Conselho de Estado Francês, de 1995, paradigma da discussão sobre os direitos fundamentais na Europa, porque acrescenta ao conceito tradicional de "ordem pública", os de "moralidade" e "dignidade da pessoa." Ao proibir "o jogo de arremesso de anões" em todo o território francês, o órgão máximo da Jurisdição Administrativa fez jus a sua posição de garantidor dos direitos fundamentais através de elaboradas construções jurisprudenciais.

PALAVRAS-CHAVE: Dignidade. Conselho de Estado Francês. Ordem Pública.

ABSTRACT: The article reviews a 1995 ruling of the French State Council which is a paradigm of the fundamental rights discussion in Europe, as it adds to the traditional concept of "public order" those of "morality" and "person's dignity". In forbidding "the midget tossing game" in the whole French territory, the Administrative Jurisdiction's supreme entity held up to its position of fundamental rights steward through elaborate judicial developments.

KEYWORDS: Dignity. French State Council. Public order.

SUMÁRIO: I. Introdução. II. A Formulação Jurisprudencial do Direito pelo Conselho de Estado; A) A dinâmica das decisões; B) Os princípios gerais de direito. III. A afirmação da dignidade da pessoa humana como componente da ordem pública; A) Antecedentes no direito positivo francês; B) Os fundamentos da decisão Morsang-Sur-Orge; C) Os elementos da ordem pública; IV. Considerações finais. V. Referências.
\end{abstract}

\footnotetext{
* Mestre e Doutora em Teoria do Estado e do Direito pela UFRGS. Professora de História do Direito, de Direito Romano e de Direito Constitucional na PUCRS. Professora de História do Direito na Faculdade de Direito do Ministério Público de Porto Alegre (FMP). Procuradora do Município de Porto Alegre. Coordenadora do Centro de Estudos de Direito Municipal (CEDIM) da PGM. E-mail: tabordamaren@yahoo.com.br.
} 
SUMMARY: I. Introduction; II. The Judicial Formulation of Law by the State Council; A) The dynamics of decisions; B) The general principles of Law; III. The affirmation of human being dignity as a component of public order; A) Precedents in French legislation; B) The underpinning of the Morsang-Sur-Orge ruling; C) The public order elements; IV. Final remarks; V. References.

\section{INTRODUÇÃO}

O Conselho de Estado Francês, em 27 de outubro de 1995, no exercício de sua competência contenciosa, julgou um caso que se tornou famoso, na medida em que proibiu uma atividade lícita - o "jogo de arremesso de anões" - sob o argumento de que tal espetáculo atentava "contra o respeito à dignidade da pessoa humana". ${ }^{1} \mathrm{O}$ jogo de arremessar anões consiste em um espetáculo em que os espectadores arremessam o mais longe possível, um anão vestido com um traje que permite ao mesmo tempo prendê-lo pelos pulsos e protegê-lo na queda sobre um tapete de recepção. Tal atração começou a se desenvolver na França, no início dos anos 90, principalmente nas danceterias e provocou uma exploração comercial à qual se prestava a própria pessoa, ao fazer-se seu objeto. Os prefeitos de Morsang-Sur-Orge e de Aix-en-Provence proibiram o espetáculo. A empresa produtora e um anão chamado M. Wackeneim recorreram da decisão ao Tribunal Administrativo de Versailles, que pronunciou a anulação da decisão, sob o fundamento de que os prefeitos excederam em seus poderes de polícia. O Conselho de Estado, no entanto, admitiu a legalidade das medidas adotadas pelos prefeitos. Em outras ocasiões, o Conselho de Estado já sublinhara a necessidade de preservar a "dignidade da pessoa"” e lembrara "os princípios deontológicos fundamentais relativos ao respeito à pessoa humana, que se impõem ao médico em sua relações com seu paciente (e) não cessam de se aplicar com a morte deste." ${ }^{3}$

Em que pese a existência de disposições legislativas e constitucionais versando sobre o tema, tais como a lei de 30 de setembro de 1986, relativa à liberdade de comunicação, limitando tal liberdade "na medida requerida ... pelo respeito à pessoa humana"; lei que introduziu o art. 16 no Código Civil Francês, segundo o qual "a lei assegura a primazia da pessoa, proíbe qualquer ataque à dignidade desta e garante o respeito do ser humano desde o início de sua vida" e decisão n ${ }^{\circ}$ 94-343/344, de 27 de julho de 1994, do Conselho Constitucional que, apoiando-se na primeira frase do preâmbulo da Constituição de 1946, considerou ser a "salvaguarda da dignidade da pessoa humana contra toda forma de sujeição e de degradação um princípio com valor constitucional", tal decisão é considerada um marco na proteção dos direitos fundamentais, porque ela afirma que o respeito à dignidade da pessoa humana é parte da ordem pública que o poder de polícia tem a finalidade de assegurar. Com isso, a discussão sobre a dignidade da pessoa ganhou novos contornos e conteúdos, porque o princípio, de valor constitucional, foi auferido em uma situação concreta.

\footnotetext{
${ }^{1}$ Texto da decisão 27 oct. 1995, Commune de Morsang-Sur-Orge in: LONG, WEIL, BRAIBANT, DEVOLVÈ e GENEVOIS. Les grands arrêts de la jurisprudence administrative. $13^{\mathrm{a}}$ édition. Paris: Dalloz, 2001, p. 768 e ss. As referências aos acórdãos do Conselho de Estado Francês feitas ao longo do texto foram retiradas desta obra. ${ }^{2}$ Acórdão de 11 julho, 1990, Ministre des affaires sociales et de l'emploi c. SyndicatC.G.T. de la Société Griffine-Maréchal.

${ }^{3} 2$ de jul. 1993, Milhaud, a propósito da publicação da fotografia do corpo da vítima de um assassinato.
} 
Tal acórdão se presta para um exame mais acurado das formas de proteção aos direitos fundamentais (diversas conforme a tradição jurídico-constitucional em que estão inseridas), bem como dos diferentes sistemas de controle judicial da Administração e de controle de constitucionalidade, em razão da particularidade do sistema francês.

De fato, dado o "legicentrismo" do constitucionalismo francês e a sua tradição política, é o Conselho de Estado, submergido das ruínas do Antigo Regime, afirmado pela organização da Jurisdição Administrativa no séc. XIX, o órgão que conhece, em última instância, os lítígios entre os cidadãos e o Estado.

Na medida em que, na França, o controle de constitucionalidade dos atos normativos (sobretudo leis e diplomas a ela assemelhados) é feito por um órgão político e não há um controle jurisdicional de constitucionalidade, ou uma justiça constitucional autônoma, é na Jurisdição Administrativa que, em grande medida, se desenvolvem os princípios e regras que delimitam a atuação estatal e protegem os direitos fundamentais dos cidadãos.

Isso é assim porque a competência do Conselho Constitucional é restrita a um contencioso normativo (abstrato, facultativo para as leis ordinárias e compromissos internacionais e obrigatório para as leis orgânicas e regulamentos das assembléias parlamentares), ao contencioso eleitoral e em matéria de referendos (julga a regularidade de eleições, os regimes de elegibilidade e de incompatibilidades parlamentares), além de uma competência consultiva (responde quando é consultado pelo Chefe de Estado sobre a aplicação da Constituição e sobre os textos relativos à organização do escrutínio para a eleição do Presidente da República e o referendo).

Feitas estas considerações, forçoso é reconhecer que, na França, o contencioso dos direitos fundamentais bem como o controle material de constitucionalidade foi feito, até 1958, pela Jurisdição Administrativa e mesmo a adoção de um sistema formal de controle de constitucionalidade não alterou este estado de coisas, uma vez que o Conselho Constitucional faz um controle prévio dos atos normativos e nunca um controle a posteriori. Isso não significa, contudo, que o Conselho Constitucional não tenha tido um papel fundamental na consolidação do Estado de Direito na França, pelo contrário: este órgão, ao interpretar a Constituição e as leis, acabou, juntamente com o Conselho de Estado, afirmando princípos jurídicos que permeiam toda a discussão em torno da proteção à dignidade da pessoa humana. ${ }^{4}$

Advém daí que, o Conselho de Estado, na França, é o artesão do Estado de Direito e, mesmo com a criação do Conselho Constitucional, pela Constituição da

${ }^{4}$ Comparando-se os diversos sistemas de controle de constitucionalidade das leis, constata-se que estes podem ser puros, especiais ou mistos. O controle puramente jurisdicional é o de tipo norte-americano, que se dá através do Poder Judiciário, em todas as suas instâncias, funcionando a Suprema Corte como tribunal constitucional, restringindo-se ao controle difuso de constitucionalidade. Nos sistemas especiais, também chamados de controle político (sistema defendido por Kelsen, adotado na Áustria, Alemanha, Espanha, Portugal, Itália e outros), o controle se dá através de órgão constitucional - Tribunal ou Corte Constitucional e pode se restringir à apreciação prévia de atos normativos leis (caso da França). Já o sistema de controle misto, adotado no Brasil, inclui tanto o controle jurisdicional difuso, em todas as instâncias do Poder Judiciário, com decisão, em última instância, do Supremo Tribunal Federal, por meio de recurso extraordinário (CF, art. 102, III), como o controle concentrado, através de ação direta ao STF (CF, art. 103). 
V República, de 4 de outubro de 1958, continua a ser o único órgão autorizado a julgar os litígios entre o Estado e os cidadãos, quer dizer, o órgão em que se processa o contencioso dos direitos fundamentais.

Foi o Conselho de Estado, no exercício de sua competência constitucional, que desenvolveu a doutrina dos Princípios Gerais de Direito e, juntamente com o Conselho Constitucional, a teoria da aplicabilidade dos Princípios Fundamentais reconhecidos pelas leis da República, a partir de construções lógicas muito próprias, em que se adota, basicamente, o raciocínio finalístico. Postas estas questões, este estudo, em sede de Teoria da Constituição, no tema Direitos Fundamentais, tem a intenção de compreender as bases institucionais e teóricas do referido acórdão e o alcance da concretização do princípio da proteção à dignidade da pessoa humana feita pelo Conselho de Estado.

Para alcançar tal objetivo, é preciso fazer uma apreciação, ainda que sintética, do desenvolvimento da Teoria dos Princípios gerais do Direito e da Teoria dos Princípios Fundamentais reconhecidos pelas leis da República,(I) de modo a ressaltar que a decisão ora comentada, além de constituir um prolongamento de situações estabelecidas em direito positivo, é considerada uma "novidade" em razão das circunstâncias em que ela foi emitida (II).

II. A FORMULAÇÃO JURISPRUDENCIAL DO DIREITO PELO CONSELHO DE ESTADO

\section{A. A dinâmica das decisões}

O Conselho de Estado, em geral, não está habituado a expor todas as deduções jurídicas que motivaram suas decisões, mas isso não quer dizer que a aplicação dos princípios gerais do direito seja fruto de sua arbitrariedade, porque a inspiração para a criação de novas normas vem das leis em vigor e da opinião geral. Daí que o Tribunal não aplique um princípio geral que não possa, de alguma forma, ser deduzido da legislação existente e repousar sobre um largo consenso (GENEVOIS, 1980, p. 281). Após a segunda guerra, contudo, o CE apenas tem afirmado a existência de "princípios gerais de direito aplicáveis mesmo na ausëncia de textos”, sem dizer expressamente qual princípio aplicou.

Considerando o modo como tais princípios são elaborados, há que se distinguir as duas funções paralelas da alta corte da Jurisdição Administrativa, quais sejam, uma função obrigatória, geral, aquela de dar solução aos litígios (jurisdicional), e outra, ocasional, “de participar da criação de regras de direito positivo” (jurisprudencial). (ROUVILLOIS, 1990, p. 1819). A função ‘jurisprudencial’ se torna relevante quando ela permite o exercício de função 'jurisdicional’, e a lógica de pensar nela envolvida não é, via de regra, o ‘ silogismo de raciocínio', e sim o denominado ‘silogismo de construção’. O primeiro modo de pensar é típico de sistemas jurídicos em que a lei escrita é a fonte primordial do direito (caso do direito francês) e a sua finalidade é determinar a solução a partir de uma regra e do caso dados. Já o segundo modo tem por finalidade estruturar a decisão, a lhe conferir uma forma lógica suscetível de satisfazer o que é judiciável. Daí que Rouvillois afirme ser a existência de uma premissa maior (uma regra aplicável) “a condição necessária e suficiente para o 
exercício da função jurisdicional”. Ao inverso, a ausência de uma regra aplicável faz com o que o juiz deva "encontrar", isto é, criar, uma norma que possa aplicar. Tal função jurisprudencial (excepcional) exclui a forma da subsunção (raciocínio silogístico) e, com isso, se pode afirmar que é sempre prévia aquela dita "normal” (jurisdicional) e só surge diante de uma lacuna no ordenamento jurídico.

Ainda que juristas como Kelsen não reconheçam a existência de "lacunas” no ordenamento jurídico, ou no máximo consintam na existência de lacunas subjetivas, fictícias - o juiz inventa a lacuna (ausência de regra) quando, na aplicação da ordem jurídica no caso concreto, esta conduz à resultados não satisfatórios - o fato é que a jurisprudência do Conselho de Estado alude a elas, quando exerce a função jurisprudencial (criadora de direito). Ditas lacunas subjetivas podem ser de dois tipos: ou não existe regra aplicável, ou a regra existe, mas o estado atual do direito faz com que a regra antiga não possa mais, objetiva e juridicamente, ser aplicada. O caso da proibição do jogo de arremesso de anões ilustra claramente esta segunda hipótese, pois existia uma regra legal a ser aplicável, qual seja, a aquela que determina que o poder de polícia dos prefeitos se exerce na ausência de polícias especiais e ante de circunstâncias locais. A Corte de Versailles, aliás, anulou a decisão de proibição do espetáculo, emitida pelo prefeito de Morsang-sur-Orge sob este argumento (há uma polícia especial e não há circunstâncias locais). A assembléia do contencioso do Conselho de Estado, no entanto, entendeu que tal motivo é "errôneo em direito", para reconhecer, expressamente que: "a autoridade investida do poder de polícia municipal podia, desde logo, interditá-la, mesmo na ausência de circunstâncias particulares.”

O tipo de raciocínio utilizado pelo Conselho de Estado para colmatar a lacuna que entendia existir é largamente finalístico e se distingue do raciocínio lógico pelo seu método: o juiz constata, primeiramente, o efeito da regra; ele apreende os termos do silogismo não do ponto de vista da premissa maior (a norma), mas do ponto de vista da conclusão. A utilização desse modo se dá porque o efeito da aplicação da regra não parece oportuno, satisfatório ou justo.

A lógica indutiva permite que o juiz compare racionalmente as medidas de justiça, de eficácia, das interpretações diversas da regra e que escolha, também racionalmente, entre as várias decisões possíveis. Em primeiro lugar, o juiz estabelece um silogismo hipotético depois de estabelecer os fatos (premissa menor); constata a existência da regra (maior) e põe a conclusão que se deduz logicamente; no segundo momento, afirma a característica nefasta, insuficiente, daquela conclusão hipotética, por relacioná-la a certas conclusões que ele mesmo determina, o que é chamado o motivo, objetivo, meta ou intenção (le but).

Considerando que a maior conduz a um resultado não mais aplicável de modo satisfatório, o juiz se remete a este resultado e reforma a formulação da premissa maior. Na decisão Ville Nouvelle Est, de 28 de maio de 1971, por exemplo, o comissário do Governo conclui: "esta conseqüência é contrária, assim, às necessidades de uma boa administração e se choca com um simples ponto de vista de equidade." 5

\footnotetext{
${ }^{5}$ Texto integral in: Les Grands Arrêts.., cit., pp. 623/635.
} 
Em síntese, a diferença entre os dois tipos de raciocínio depende do lugar, da importância de cada um deles no complexo processo de criação de novas normas. As normas referidas como premissas maiores são, muitas vezes, postas jurisprudencialmente, mais ou menos à moda dos 'precedentes' do sistema jurídico dos países de tradição inglesa (common law), e neste caso, o juiz é mais livre do que quando está diante de uma regra posta pela lei.

Ainda que parte da doutrina francesa não o admita, a jurisprudência é fonte de regras de direito para o direito administrativo francês, primeiro, porque este não foi objeto de uma codificação sistemática e, segundo, pelo próprio poder 'pretoriano' concedido ao Conselho de Estado, por delegação constitucional, qual seja, o de definir, por sua jurisprudência, as regras de direito aplicáveis aos litígios administrativos.

Desta forma, o direito aplicado pelos Tribunais Administrativos e pelo Conselho de Estado tem origem em suas próprias decisões. A acumulação das decisões, a repetição das soluções, em direito administrativo, garantiu a estabilidade desta produção jurisprudencial. Tanto é assim que dois membros do Conselho de Estado, S. Hubac e Y. Robineau, invocaram, sem hesitação, o poder criativo do juiz administrativo e diversos autores citam a criação do estatuto dos estrangeiros, o código de nacionalidade e a resolução dos problemas ligados à evolução da ética médica como fruto dessa liberdade. (HARDY, 1990, p. 455).

A utilização, pelo juiz administrativo e especialmente pelo Conselho de Estado, de regras aplicáveis mesmo no ausência de textos, é uma prova de audácia de sua parte, porque, deste modo, o juiz participa na criação de regras, ainda que tal prática devesse ser excluída em um sistema jurídico fundado sobre o direito escrito e supremacia da lei. Quando a doutrina reconhece ao juiz administrativo um poder normativo, não o faz sem alguma resistência, de modo que é freqüentemente sustentado que ao aplicar os princípios gerais de direito, o CE apenas está a constatar a sua existência: tudo se passa em teoria como se os princípios geais de direito fossem preexistentes à intervenção do juiz, que nada mais faz do que relatar a sua existência.

\section{B. Os princípios gerais de direito}

O raciocínio finalístico é complementar, indispensável ao raciocínio silogístico, e existe uma relação particular entre ele e a obra jurisprudencial do Conselho de Estado, que são os princípios gerais de direito já estabelecidos. A utilização de tais juízos (finalísticos ou teleológicos) conduz a uma ruptura, a um rompimento com a regra anterior e assim, sua função principal é a de fazer evoluir o Direito, de adaptá-lo às novas exigências.

O fato de o Conselho de Estado fundamentar suas decisões contenciosas sobre princípios não escritos é bastante tradicional, basta ver o número de decisões da primeira metade do séc. XX que não estão vinculadas expressamente a um texto legal, como, exemplicativamente: Ledochowski, de 19 de junho de 1903, afirmando o princípio do respeito aos direitos de defesa em processos disciplinares; Roubeau, de 9 de maio de 1913, sobre o princípio da igualdade diante da lei; Abdoulhoussen, de 23 de novembro de 1936, relativa ao princípio da igualdade diante dos impostos; Société l'alcool dénature de Coubert, de 1 de abril de 1938, consagrando o princípio de igualdade de tratamento entre os usuários de um serviço público; Union Corporative 
des travaillers français, de 7 de julho de 1939, relativa ao princípio da liberdade sindical e a famosa decisão Champsavoir, de 11 de dezembro de 1942, afirmando o princípio da separação dos poderes. Tal discrição pode ser explicada pela repugnância tradicional a estar ligado de modo muito estreito às suas próprias criações jurisprudenciais, por uma legítima prudência de sua parte (chama a atenção o fato de que o juiz exija o respeito não somente à literalidade dos textos legais mas também aos princípios gerais de direito), mas sobretudo em razão da "inutilidade de mencionar os princípios diretamente inspirados no regime democrático e ligados à ele em um país em que este regime não é discutido ou posto em causa pelos governantes.” (GENEVOIS, cit.)Mesmo durante o regime de Vichy, a teoria dos princípios gerais de direito foi afirmada "como uma obra construtiva da jurisprudência realizada pelos motivos superiores de equidade, a fim de assegurar a salvaguarda dos direitos individuais dos cidadãos.” (GENEVOIS, cit).

Após a Constituição de 1958, com o estreitamento das prerrogativas governamentais (que ficaram dependentes do Parlamento) e a edição de medidas restritivas ao exercício das liberdades públicas (decorrentes da guerra da Argélia), o Conselho de Estado deu à teoria dos princípios gerais de direito novos prolongamentos, de modo que a mesma foi utilizada pelo Conselho para permitir um controle sobre o Executivo, bem como sobre o exercício do poder regulamentar autônomo pelo Primeiro Ministro diante de uma habilitação a ele conferida por lei ou por via de referendo, sobre medidas que pertencem ao domínio da lei. A partir daí, o Conselho Constitucional (criado pela Constituição de 1958) acabou por tomar posição no sentido de reconhecer valor constitucional aos princípios gerais de direito. As mudanças institucionais, porém, não explicam tudo: o sucesso da teoria dos princípios gerais de direito tem dados permanentes próprios ao direito administrativo. O recurso aos princípios gerais de direito permitem ao juiz administrativo estender o conteúdo do chamado "bloco de legalidade”, respondendo, assim, aos imperativos de uma judiciosa política jurisprudencial e isso explica a dificuldade em listar expressamente tais princípios.

O catálogo dos princípios que pode ser estabelecido a partir da jurisprudência do Conselho de Estado não pode pretender ser exaustivo, porque, todos os dias, em um caso ao Conselho submetido, pode ser descoberto um novo princípio. (ODENT, 1980, p. 1708).

M. Odent distingue duas grandes categorias de princípios: aqueles ligados ä filosofia política e os que dizem respeito às regras de técnica jurídica destinadas a assegurar o respeito às pessoas.

Os princípios de filosofia política a que se refere o juiz administrativo podem estar ligados à tradição liberal, tais como o princípio da igualdade (igualdade diante das leis e dos regulamentos, igualdade de acesso aos empregos públicos, igualdade dos candidatos a um concurso, igualdade em relação ao funcionamento dos serviços públicos, igualdade diante da tributação, etc.) e o princípio das liberdades individuais e coletivas (liberdade corporal, liberdade de consciência, liberdade de opinião, de comércio e indústria, de reunião, liberdade de associação e sindical, dentre outros).

Também pertencem à categoria dos princípios de filosofia política, aqueles que dizem respeito à lógica das instituições e às necessidades da vida coletiva, tais como o princípio da unidade do Estado, os que dizem respeito à continuidade e regularidade 
dos serviços públicos e à autonomia das pessoas públicas. Além disso, ao aplicar os princípios gerais de direito no domínio social, o Conselho acabou por reconhecer uma série de princípios ligados à filosofia política, tais como aquele que proíbe a demissão de assalariada gestante e o direito de todo o indivíduo, cidadão francês ou estrangeiro, de ter uma existência familiar normal. ${ }^{6}$

Quanto à segunda categoria de princípios (que dizem respeito à técnica jurídica), o Conselho de Estado faz referência a duas espécies distintas, quais sejam, aquelas que regulam diretamente a ação administrativa e as que regulam a atividade jurisdicional. No que diz respeito aos princípios que regulam a ação administrativa, a alta Corte Administrativa desenvolveu o princípio dos direitos de defesa, o princípio em virtude do qual os atos administrativos não podem dispor senão que para o futuro, o princípio da intangibilidade das decisões administrativas individuais criadoras de direito, a regra do "non bis in idem" no que tange às faltas disciplinares, a regra de proíbe os agentes públicos de serem remunerados diretamente pelos usuários de serviço público e o princípio da especialização das pessoas públicas à determinada competência, limitada pela lei.

No que tange aos princípios de técnica jurídica que são relativos à atividade das jurisdições, dois aparecem como essenciais: aquele que afirma ter uma pessoa, com interesse justificado, a faculdade de pedir ao juiz que aprecie a legalidade de decisões que um texto legislativo decida que estas não são suscetíveis de quaisquer recursos e aquele que assegura o caráter contraditório do procedimento nas jurisdições administrativas e nas jurisdições judiciárias. Contudo, princípios como o que diz respeito ao segredo das deliberações e à coisa julgada pelas jurisdições administrativas também foram afirmados como princípios gerais de direito ligados às atividades jurisdicionais. No que diz respeito às jurisdições judiciárias, o Conselho de Estado erigiu em princípio geral de direito a publicidade dos debates judiciários e a faculdade reconhecida ao juiz de pronunciar uma astreinte em via de execução. (GENEVOIS, cit., p. 292).

Anteriormente à promulgação da Constituição de 1958, segundo a opinião dominante, os princípios gerais de direito tinham um valor legislativo, sob o fundamento de que o Conselho de Estado é um juiz que, como todos os juízes, submete-se à lei, de modo que, quando aplica um princípio não escrito e lhe confere um valor de texto de direito positivo, nada mais faz do que interpretar a vontade do legislador. (GENEVOIS, cit., p. 293) Na medida em que a Constituição de 1958 assinalou ao Poder Legislativo um domínio limitado e reconheceu como regulamentar todas as matérias não incluídas neste domínio (cf. art. 34 e 37), houve uma mudança de perspectiva para reconhecer que titular de um poder regulamentar autônomo deve respeitar os princípios gerais de direito que, por serem resultado do Preâmbulo da Constituição, se impõem a toda autoridade regulamentar mesmo na ausência de disposições legislativas. ${ }^{7}$

\footnotetext{
${ }^{6}$ Em nome deste princípio, o Conselho de Estado anulou um decreto suspendendo a entrada na França dos membros da família de trabalhadores imigrantes. Decisão Groupe d'information et de soutien des travailleurs immigrés et autres, de 8 de dezembro de 1978. Texto integral in: Les Grands Arrêts.., cit. pp. 657/668.

${ }^{7}$ Decisão Syndicat générale des Ingénieurs-Conseils, de 26 de julho de 1959. Texto in: Les Grands Arrêts.., cit., pp. 541/549.
} 
A contribuição da jurisprudência do Conselho Constitucional a este respeito não foi menos significativa, uma vez que a Corte, ao recorrer aos princípios gerais de direito em inúmeras ocasiões, lhes conferiu uma nova perspectiva. Em um primeiro momento, o Conselho Constitucional utilizou a teoria para estender o domínio de aplicação da lei, interpretando os artigos 34 e 37 da Constituição. Com isso, utilizou a teoria dos princípios gerais como elemento da repartição de competências entre a lei e o regulamento (decisões de 26 de junho de 1969, de 24 de outubro de 1969 e de 21 de dezembro de 1972). Como conseqüência destas decisões, resulta que os princípios gerais de direito têm uma existência independente do artigo 34 da Constituição e, que, em alguns casos, tais princípios têm apenas valor legislativo. (GENEVOIS, cit., p. 295).

Após uma decisão de 16 de julho de 1971, relativa à liberdade de associação, o Conselho Constitucional passou a recorrer à teoria dos princípios gerais de direito em sede de controle de constitucionalidade e, neste caso, os princípios gerais de direito alcançam valor constitucional. Tais princípios têm três origens, a saber: o texto da Constituição, o Preâmbulo e os textos legais a que ela se refere, de modo que os certos princípios são deduzidos diretamente da Constituição, como o princípio da igualdade, formulado de diversos modos ( $\operatorname{art} .2^{\circ}$ e art. $3^{\circ}$ ) e o princípio da independência da autoridade judiciária afirmado pelo artigo $64 .^{8}$

No que diz respeito à interpretação do Preâmbulo da Constituição, o Conselho Constitucional acabou por desenvolver a noção de 'princípios fundamentais reconhecidos pelas leis da República', expressão que se encontra no Preâmbulo da Constituição de 1946, recepcionado pela Constituição de 1958. De acordo com esta "nova tese”, os princípios fundamentais reconhecidos pelas leis da República estão ancorados na Constituição $^{9}$ e, na medida em que a Corte Constitucional não tem o monopólio da interpretação dos casos difíceis, a juiz administrativo acabou por ter, nos princípios de valor constitucional, uma fonte de inspiração privilegiada. O Conselho Constitucional, entretanto, tornou precisos os critérios de identificação de tais princípios, de modo que, para serem reconhecidos, devem ter sido postos pelo legislador constituinte como “essenciais” e não podem ser derrogados ulteriormente. Assim, no estado atual da jurisprudência do Conselho Constitucional e do Conselho de Estado, os princípios gerais de direito podem adquirir, de acordo com o caso, valor constitucional, valor legislativo, ou mesmo valor regulamentar, quando se tratarem de simples regras de procedimento.

A distinção entre 'princípios gerais de direito' e 'princípios fundamentais reconhecidos pelas leis da República’ não é clara: alguns princípios gerais de direito são ligados, na jurisprudência do Conselho de Estado e do Conselho Constitucional,

\footnotetext{
${ }^{8}$ Décision n ${ }^{\circ}$ 71-44 DC du 16 juillet 1971. (.....) Considérant, enfin, que les autres dispositions de ce texte ne sont contraires à aucune disposition de la Constitution; Décide: ARTICLE PREMIER - Sont déclarées non conformes à la Constitution les dispositions de l'article 3 de la loi soumise à l'examen du Conseil constitutionnel complétant les dispositions de l'article 7 de la loi du 1er juillet 1901 ainsi que les dispositions de l'article 1er de la loi soumise au Conseil leur faisant référence. ARTICLE 2 - Les autres dispositions dudit texte de loi sont déclarées conformes à la Constitution. ARTICLE 3 - La présente décision sera publiée au Journal officiel de la République française.

9 “Idem: 2. Considérant qu'au nombre des principes fondamentaux reconnus par les lois de la République et solennellement réaffirmés par le préambule de la Constitution il y a lieu de ranger le principe de la liberté d'association (.....).”
} 
aos princípios reconhecidos pelas leis da república, como no caso Dame Peynet (C.E. 8 de junho de 1973). De qualquer modo, há que se ressaltar a importância da teoria dos princípios gerais de direito no direito administrativo francês porque, desenvolvida pela Conselho de Estado para melhor controlar a ação da Administração e atenuar a insuficiência de textos, ela acabou tendo prolongamentos na jurisprudência da Corte Criminal da Corte de Cassação e também na do Conselho Constitucional.

Sem contestar a utilidade de tal formulação, há que se reconhecer, entretanto, que o valor jurídico das disposições do preâmbulo da Constituição de 1958 e os textos aos quais se refere, perde um pouco a sua importância diante da noção de princípios que se aplicam mesmo na ausência de textos, o que bem demonstra os recortes entre o direito escrito e os princípios gerais. A noção de "princípios fundamentais reconhecidos pelas leis da República” e muito imprecisa para não ser ela mesma interpretada à luz da teoria dos princípios gerais de direito, o que é o caso do reconhecimento do princípio do direito à uma existência familiar normal - o que serviu de suporte foi a formulação de "princípios particularmente necessários ao nosso tempo “ - , deduzido de um alínea bastante geral o Preâmbulo da Constituição de 1946: "a nação assegura ao indivíduo e à família as condições necessárias ao seu desenvolvimento”.

De outra parte, o Conselho de Estado e o Conselho Constitucional são particularmente rigorosos na terminologia que empregam. Se há um valor constitucional, legislativo, regulamentar ainda que se trate de regra geral de procedimento, conforme o caso, é interessante fazer desaparecer o risco de confusão entre estas três categorias. Daí, a remissão de ordem não é inútil, porque supõe que pode ser eficaz e que há concordância entre as posições do Conselho de Estado e aquelas adotadas pelo Conselho Constitucional, se bem que isso nem sempre seja o caso, como na circunstância em que a Corte Constitucional não erigiu em princípio com valor constitucional aquele segundo o qual todo ato administrativo pode ser objeto de recurso por excesso de poder. ${ }^{10}$

Resta clara a importante posição que ocupa a farta jurisprudência do Conselho de Estado no processo de criação do direito administrativo francês. O juiz administrativo foi, com efeito, o principal artesão da autonomização do direito administrativo em relação ao direito civil principalmente no que toca ao regime de responsabilidade das pessoas públicas e à noção de serviço público. Mas não só: não havendo um contencioso

\footnotetext{
${ }^{10}$ Décision n 80-119 DC du 22 juillet 1980. Loi portant validation d'actes administratifs.”(...) Considérant qu'il résulte des dispositions de l'article 64 de la Constitution en ce qui concerne l'autorité judiciaire et des principes fondamentaux reconnus par les lois de la République en ce qui concerne, depuis la loi du 24 mai 1872, la juridiction administrative, que l'indépendance des juridictions est garantie ainsi que le caractère spécifique de leurs fonctions sur lesquelles ne peuvent empiéter ni le législateur ni le Gouvernement ; qu'ainsi, il n'appartient ni au législateur ni au Gouvernement de censurer les décisions des juridictions, d'adresser à celles-ci des injonctions et de se substituer à elles dans le jugement des litiges relevant de leur compétence. Mais considérant que ces principes de valeur constitutionnelle ne s'opposent pas à ce que, dans l'exercice de sa compétence et au besoin, sauf en matière pénale, par la voie de dispositions rétroactives, le législateur modifie les règles que le juge a mission d'appliquer ; qu'ainsi le fait que la loi soumise à l'examen du Conseil constitutionnel intervient dans une matière ayant donné lieu à des recours actuellement pendants n'est pas de nature à faire regarder cette loi comme non conforme à la Constitution; (....) Décide: Art 1er - La loi portant validation d'actes administratifs soumise à l'examen du Conseil constitutionnel est déclarée conforme à la Constitution. Art 2 - La présente décision sera publiée au Journal officiel de la République française.” In: www.conseil-constitutionnel.fr, acessado em 20 de agosto de 2007.
} 
dos direitos fundamentais feito pelo Conselho Constitucional, é o Conselho de Estado, vale dizer, a Jurisdição Administrativa que acabou por também desenvolver e afirmar o princípio da dignidade humana , além de uma série de outros princípios e normas de direito fundamental.

\section{A AFIRMAÇÃO DA DIGNIDADE DA PESSOA HUMANA COMO COMPONENTE DA ORDEM PÚBLICA}

Pela decisão Commune Morsang -Sur- Orge, o respeito à dignidade humana foi objeto de um reconhecimento na jurisprudência administrativa francesa, para ser aplicado a uma atividade lícita que atenta contra ela. Tal afirmação, na verdade, constitui um prolongamento de soluções já admitidas no direito positivo francês.

\section{A. Antecedentes no direito positivo francês}

O respeito à dignidade da pessoa humana não tem seu conteúdo explicitado na Constituição francesa: a referência que o Conselho de Estado fez foi ao texto da Declaração de Direitos do Homem e do Cidadão, de 1789 e ao Preâmbulo da Constituição de 1946. O princípio, inicialmente às decisões envolvendo atentados contra a honra e os crimes contra a Humanidade, passou a ter valor conteúdo definido conferidos pelo direito positivo. Com a decisão do Conselho Constitucional, de 27 de julho de 1994, a proteção à dignidade humana foi erigida em princípio de valor constitucional. Nas considerações, afirma-se que as leis objeto de controle (lei relativa ao respeito do corpo humano e lei relativa à utilização de embriões humanos, à reprodução assistida e ao diagnóstico pré-natal) "enunciam um conjunto de princípios entre os quais figuram a primazia da pessoa humana, o respeito do ser humano, o respeito ao ser humano que está começando sua vida, a inviolabilidade, a integridade e a ausência de caráter patrimonial no corpo humano, bem como a integridade da espécie humana; que os princípios assim afirmados tendem a assegurar o respeito ao princípio constitucional de salvaguarda da dignidade da pessoa humana."11 A fundamentação da decisão também afirma que tais princípios se impõem pela marcha do progresso, pelo desenvolvimento de novas tecnologia, pela constituição de novos costumes e renovação das gerações. De acordo com Robert, (ROBERT, 1998, p. 29), o Conselho Constitucional estimou que o texto das leis examinadas salvaguarda a dignidade humana contra toda a forma de servidão e degradação e que toda a liberdade individual deve ser conciliada com outros princípios de valor constitucional.

A Corte ainda fez referência ao Preâmbulo da Constituição de 1946, quando repete expressões como "a nação assegura ao indivíduo e à família as condições de desenvolvimento” ou “ ela garante a criança, a mãe e a proteção da saúde”, afirmando que a proteção à dignidade da pessoa humana, noção ligada aos Direitos Humanos, ganha valor constitucional. O Conselho também fez uma relação importante da proteção

\footnotetext{
${ }^{11}$ Décision n 94-343/344 DC du 27 juillet 1994. Loi relative au respect du corps humain et loi relative au don et à l'utilisation des éléments et produits du corps humain, à l'assistance médicale à la procréation et au diagnostic prénatal. DECIDE : Article premier.- La loi relative au respect du corps humain et la loi relative au don et à l'utilisation des éléments et produits du corps humain, à l'assistance médicale à la procréation et au diagnostic prénatal sont déclarées conformes à la Constitution. Article 2.- La présente décision sera publiée au Journal officiel de la République française. Délibéré par le Conseil constitutionnel dans ses séances des 26 et 27 juillet 1994. In: www.conseil-constitutionnel.fr, acessado em 11 de junho de 2005.
} 
à dignidade da pessoa humana e as liberdades essenciais, no sentido de que estas devem aproveitar a toda pessoa humana e de que os atentados a esta dignidade podem se produzir a cada instante, a propósito de cada liberdade. ${ }^{12}$

O princípio da proteção à dignidade da pessoa não foi posto somente pelo Conselho Constitucional: numerosas leis francesas são fundadas sobre ele, tais como aquelas que dizem respeito ao direito a uma habitação decente (Lei n 90-449, de 31 de maio de 1990), o Código de Deontologia Médica (Decreto $n^{\circ}$ 95-1000, de 6 de setembro de 1995), além das leis no 94-630, de 25 de julho de 1994 e nº 94-653, de 29 de julho de 2994, relativamente ao respeito do corpo humano e à utilização de elementos e produtos do corpo humano, e à reprodução assistida, respectivamente. ${ }^{13}$

\section{B. Os fundamentos da decisão Morsang-Sur-Orge}

Na fundamentação da decisão de 27 de outubro de 1995, quando o Conselho de Estado considera que a atração "lançamento de anão”, "por seu próprio objeto, fere a dignidade da pessoa humana”, utiliza um fundamento essencialmente filosófico, ligado à concepção da natureza humana, que encontra suas raízes na doutrina da Igreja, (o homem foi criado à imagem e semelhança de Deus) (BARZOTTO, 2003, p. 34.) e na filosofia kantiana: "o homem considerado como persona, é dizer, como sujeito de uma razão prático-moral, está situado acima de todo preço; porque como tal (homo noumenon) não pode valorar-se só como meio para fins alheios, inclusive para os seus próprios fins, senão como um fim em si mesmo, é dizer, possui uma dignidade (um valor interno absoluto) graças ao qual infunde o respeito a si mesmo e todos os demais seres racionais do mundo(...)”. (KANT, 1999, pp. 289/299)

A tradução do preceito na ordem jurídica é relativamente recente, pois, ainda que a Declaração dos Direitos do Homem e do Cidadão considere os direitos naturais inalienáveis e sagrados, não faz menção expressa ao princípio. No máximo, se pode considerar que tais direitos são inseparáveis de uma dignidade que, embora não expressa, está, pelo menos, subjacente. ${ }^{14}$ Foram os fenômenos da barbárie nazista e o desenvolvimento da biomedicina que levaram o princípio a uma formulação jurídica.

\footnotetext{
${ }^{12}$ Até a DC no 2001-446 DC du 27 juin 2001, estava em aberto a questão de saber o momento em que nasce a "pessoa humana”, isto é, se o embrião ou o feto eram destinatários da proteção. A decisão de 2001 entendeu que até 12 semanas de gestação, é possível o aborto, sob o argumento de que "a lei não pode, no estado dos conhecimentos e das técnicas, romper o equilíbrio que o respeito à Constituição impõe entre, de uma parte, a salvaguarda da dignidade da pessoa humana contra toda a forma de degradação e, de outra parte, a liberdade da mulher que decorre do art. $2^{\circ}$ da Declaração dos direitos do Homem e do Cidadão”.

${ }^{13}$ Textos do decreto referido e leis in: ROBERT, Jacques, OBERDORFF, Henri. Libertés fondamentales et droits de l'homme. 2a . Édition. Paris: Montchrestien, 1995, pp. 373 e p. 388/ a 416..

${ }^{14}$ Segundo Barzotto, a dignidade da pessoa “é o termo que expressa o princípio subjacente à justiça social: a pessoa humana é digna, merecedora de todos os bens necessários para realizar-se como ser concreto, individual, racional e social” e seu valor está presente no desenvolvimento da civilização ocidental, já que "a consciência de um dever de justiça para como o outro em virtude da sua simples humanidade foi formulado de vários modos”, a saber: é um dos preceitos do direito, segundo Ulpiano, pois honeste vivere só pode ser interpretado como uma referência à humanitas presente no outro; é o conteúdo mesmo do imperativo categórico de Kant: "age de tal modo que uses a humanidade, tanto na tua pessoa como na pessoa de qualquer outro, sempre e simultaneamente como fim e nunca simplesmente como meio” , bem como a "regra de ouro" do pensamento cristão: "como querei que os outros vos façam, fazei também a eles”. In: A Justiça Social...., cit. p. 42.
} 
Assim, vários instrumentos internacionais acabaram por reconhecer-lhe os elementos, tais como o Pacto Internacional sobre direitos civis e políticos, de 16 de dezembro de 1966, afirmando que tais direitos "decorrem da dignidade inerente à pessoa humana”, a Convenção européia de salvaguarda dos direitos do homem e das liberdades fundamentais, de 4 de novembro de 1950, que, em seu art. $3^{\circ}$, proíbe expressamente "tratamentos desumanos ou degradantes" e a decisão Royaume-Uni, Série A $335 B \S 44$, da Corte européia dos direitos do homem, asseverando que a essência mesma da Convenção é “o respeito à dignidade e à liberdade humana”.

O legislador francês também fez referência ao "respeito à pessoa humana” e à "primazia da pessoa”, que "proíbe qualquer ataque à dignidade desta e garante o respeito do ser humano desde o início de sua vida" nas leis de 30 de setembro de 1986 e de 29 de julho de 1994, relativas à liberdade de comunicação e ao respeito do corpo humano, respectivamente. Na Jurisprudência do Conselho de Estado, foi igualmente sublinhado "a necessidade de preservar a dignidade da pessoa" no caso Ministre des affaires sociales et de l'emploi c. Syndicat C.G.T. de la Société GriffineMárechal, julgado em 11 de julho de 1990.

A ‘novidade' da decisão Morsang-Sur-Orge reside nas circunstâncias em que ela foi emitida, porque, até então, o direito positivo considerara tão somente os atentados às pessoas feitos pelos poderes públicos e não as violações resultantes do comportamento de particulares, com a concordância do interessado: os espectadores e os organizadores do espetáculo expõem-se a práticas contestadas, sem exercer pressão sobre quem é objeto do jogo. Este (o anão), na medida em que consente plenamente com a atividade e encontra nela a sua subsistência, pôde contestar as decisões municipais alegando que ao proibir-se o espetáculo, estavam-no privando de sua remuneração.

Os argumentos da sociedade organizadora dos espetáculos e das pessoas lançadas não foram suficientes, aos olhos do Conselho de Estado, para estabelecer que tal prática não é atentatória à dignidade humana, porque "esta deve ser respeitada não só pelas autoridades, mas deve sê-lo tanto pelos indivíduos em suas relações entre eles quanto por cada um por si próprio. Ninguém pode consentir com sua própria degradação.” (LONG, cit., p. 771). Precisamente por que o lançamento de anão torna uma pessoa objeto nas mãos de outros em razão de sua deficiência (esta é o elemento da atração porque sua deformidade suscita curiosidade e até perversidade), o Conselho de Estado considerou, conforme a justificativa do relator, M. Frydman, que, por seu próprio objeto, "essa atração atenta contra a dignidade da pessoa humana”.

O passo decisivo, contudo, foi dado pela consideração de que é preciso que o respeito à dignidade da pessoa humana faça parte da ordem pública, de modo que o poder de polícia (que tem por finalidade assegurá-la), possa exercer-se. Contudo, como nenhum dos elementos que compõe a ordem pública (boa ordem, segurança, tranqüilidade e salubridade pública) fora violado pelo lançamento do anão (este se prestava livremente a essa exibição; foram tomadas precauções que protegiam-no dos acidentes, nem a saúde nem a higiene do interessado ou dos espectadores estavam ameaçadas; a tranqüilidade pública também não o estava, uma vez que o exercício não provocava tumulto e se incômodos causavam à vizinhança, era pela altura da 
música das danceterias e não pelo lançamento do anão em si), a questão foi perspectivada a propósito da moralidade pública. Assim, na medida em que a moralidade pública ultrapassa a ordem material e exterior que, conforme Hauriou, cobre somente a ordem pública, ela foi unida à ordem moral que um Estado liberal se recusa a impor. O Tribunal, então, construiu a sua decisão a partir da dimensão institucionalista da ordem jurídica e, em uma época da "relatividade dos valores”, acabou por tomar posição em favor daquele que considerou o mais fundamental deles. ${ }^{15}$

\section{Os elementos da ordem pública}

A trilogia dos elementos que constituem a ordem pública, na França, tem origem nas fórmulas de leis antigas (todas referidas nas considerações do acórdão). Outros elementos, no entanto, são atualmente, acrescentados, como a salvaguarda da estética e as questões de ordem moral. No acórdão do Conselho de Estado de 23 de outubro de 1936 Union parisiente des syndicats de l'imprimerie, justificou-se a proibição de distribuição de impressos na via pública sob o fundamento da salvaguarda da estética; na decisão Club indépendant châlonnais, de 7 de novembro de 1924, o Tribunal considerou legal uma proibição de luta de boxe em função de ser "contrária à higiene moral” . No acórdão Société “les films Lutétia”, de 18 dezembro de 1959, o Conselho de Estado admitiu que a projeção de um filme pode ser interpretada "em razão do caráter imoral do dito filme e de circunstâncias locais.” ${ }^{16}$

A moralidade pública, ligada a noção de boa ordem, justificou igualmente medidas de polícia para lutar contra a prostituição, (CE 17 dez. 1909, Chambre Syndicale de la corporation des marchands de vins et liquoristes de Paris,), mas a menção da "boa ordem" ao lado daquela da moralidade ou da decência pode parecer puramente formal. Como asseveram os autores da obra Les Grands Arrêts , “o acórdão não vai até aí. No momento em que Frydman sustentava "que o respeito à dignidade humana constitui ele próprio um dos componentes essenciais da moralidade pública,” o Conselho de Estado considera diretamente "que o respeito à dignidade da pessoa humana é um dos componentes da ordem pública”, sem mencionar a moralidade pública. Evita, assim, fazer referência a uma noção aproximativa e difícil de manejar em matéria de polícia”. (LONG, cit., p. 773).

Certo é, no entanto, que esta referência insere o respeito à dignidade da pessoa humana na noção de ordem pública, de modo que, sem referência à moralidade (e a fortiori à moral), este respeito é parte da ordem pública porque esta não se limita à

\footnotetext{
${ }^{15}$ A teoria institucionalista do Direito, formulada por Maurice Hauriou, é aquele segundo a qual a Administração é uma instituição, isto é, uma idéia de obra ou de empreendimento que se realiza e dura juridicamente no meio social; para a realização desta idéia, um poder se organiza, e, de outra parte, entre os membros do grupo social interessados na realização da idéia, se produzem manifestações de comunhão dirigidas aos órgãos do poder e às regras de procedimento. In: Précis de droit Administrafi et de droit public. 12e Édition. Revue et mise à jour par André Haurion. Réédition présentée par Pierre Devolvé et Frank Moderne. Paris: Dalloz, 2002, p. VI.

${ }^{16}$ Cf. Les Grands Arrêts, cit., pp. 550 e ss. Em 2000, o acórdão Association Promouvoir, M. et Mme. Mazaudier, anulou a decisão que concedia um visto de exploração ao filme "Baise-moi" porque este, "composto, no essencial, de uma sucessão de cenas de grande violência e de cenas de sexo não simuladas", "constitui, assim, uma mensagem pornográfica e de incitação à violência... que poderia depender das disposições do art. 227.24 do Código Penal.”. Cf. Les Grands Arrêts, cit., p. 772
} 
segurança, à salubridade e à tranqüilidade públicas: “cobre uma concepção do homem que a sociedade deve respeitar, e os poderes públicos fazer respeitar.”

A grande inovação da decisão foi, contudo, a afirmação de que os prefeitos, no exercício do poder de polícia geral, podem tomar uma medida tão grave como a interdição, mesmo havendo uma polícia especial e na ausência de circunstâncias locais. Nessa passagem, ressalta a lógica finalística da decisão, porque, diante de um regra que poderia ser aplicada, o Conselho de Estado deixou de fazê-lo, ante à consideração de que o espetáculo era contestado em si mesmo, em qualquer local que fosse: era em nível nacional que o problema se colocava. O espetáculo de 'lançamento de anão’ está submetido a uma legislação especial, que o classifica como “espetáculos em feiras, exibições de cantos e dança em lugares públicos e todos os espetáculos de curiosidades e variedades” (Regulamento de 13 de outubro de 1945), pois dúvida não há que se trata de um espetáculo de curiosidade (doentia). A existência de uma polícia especial pode excluir a intervenção das autoridades de polícia geral (como o prefeito), mas na espécie, isso não ocorreu: ao proibir o espetáculo em virtude de seu poder de polícia geral (que lhe é atribuído para fazer face às circunstâncias que se produzem no território do município), o prefeito voltou ao princípio da polícia especial (que lhe permitia a adoção de medidas particulares como a recusa de autorização e que faz da interdição o princípio, e da autorização a exceção), sem que nenhum pedido de autorização tenha sido feito. Neste caso, a polícia geral reforçou a polícia especial, mas este aspecto sequer foi exprimido pela decisão que "não teve necessidade de examinar outros meios de petição”, nem mesmo destacado em qualquer outra parte do acórdão. Assim, a solução da controvérsia poderia ter partido das autoridades encarregadas do poder de policia em nível nacional (o Primeiro Ministro), mas

"não era evidente juridicamente que essas autoridades teriam devido adotá-la (...) a ausência de medida em nível nacional para um atentado à ordem pública, que pode ter efeito em todo o território, não pode privar as autoridades locais de polícia do poder de tomar, no âmbito de sua competência, as medidas que são necessárias para assegurar a ordem pública se uma atividade atenta contra ela.” (LONG, cit., p. 774).

O Conselho de Estado apreciou, então, que o efeito da aplicação da regra não era satisfatório e, afirmando a característica nefasta da conclusão hipotética - a ausência de poderes para tomar medida que assegurasse a ordem pública - acabou por reformular a premissa maior, isto é, considerou que os prefeitos, investidos do poder de polícia municipal, podiam, desde logo, interditar o espetáculo, "mesmo na ausência de circunstâncias locais particulares”.

Em razão do raciocínio finalístico utilizado, o Conselho de Estado pode admitir a mais grave medida de polícia - interdição pura e simples da atração - porque, no caso, não havia liberdades que pudessem ser opostas, nem outra solução que pudesse ser adotada. Relativamente às liberdades, várias delas podiam ser invocadas em favor do jogo, como por exemplo, que a atividade era lícita (não havia tipificação penal) e que a pessoa que se presta à exibição estava exercendo a sua liberdade individual. 
Todavia, em matéria de polícia, esses argumentos não procedem. Relativamente ao primeiro argumento, não procede porque atividades protegidas pela lei podem ser objeto de medidas de polícia; ${ }^{17}$ no que diz respeito à liberdade individual, o Conselho de Estado já descartara o argumento quando considerou obrigatório o uso de cinto de segurança porque estimou que tal uso tem por finalidade "reduzir as conseqüencias dos acidentes da estrada."18 No caso, “o atentado à dignidade da pessoa humana, com o qual ninguém pode concordar (...), constitui um atentado contra a sociedade, visto que o respeito a essa dignidade faz parte da ordem pública.” (LONG, cit., p. 776). Ademais, a liberdade do trabalho, comércio e indústria não podem ser consideradas obstáculos para que tal atividade seja proibida, "se esta medida é necessária para remediar os inconvenientes que o modo de exercer a profissão (...) pode apresentar para a circulação e para a ordem pública.” (LONG, cit., p. 776).

Enfim, nos termos da argumentação do Conselho de Estado, mesmo que se tomem precauções para a segurança do anão e dos espectadores, a atração, por sua natureza, fere a dignidade da pessoa humana e, por isso mesmo, a única medida adequada é a interdição. De outra parte, quando a decisão assegura que "compete à autoridade investida de poder de polícia tomar toda medida para prevenir um atentado contra a ordem pública”, acaba por afirmar que as autoridades têm não só o poder, mas o dever de agir em caso de atentado à dignidade da pessoa humana.

\section{CONSIDERAÇÕES FINAIS}

A decisão Morsang-Sur-Orge não é só paradigmática porque concretizou o princípio da proteção à dignidade da pessoa humana, mas porque reafirma a tradição do Direito Constitucional Francês, qual seja, aquela em que os direitos fundamentais dos cidadãos são protegidos pela Jurisdição Administrativa. Esta tradição se vincula à experiência constitucional do continente europeu como um todo, que afirmou ser a proteção jurídica da liberdade uma 'proteção constitucional' porque a Constituição deveria ser garantida por um juiz. O que se protegia era as posições do indivíduo contra o Estado - status negativo - sob nome de "catálogo de direitos fundamentais", isto é, especificação jurídica dos postulados filosóficos do Iluminismo.

Para realizar-se a tutela jurídica do cidadão no âmbito do Direito Público, afirmou-se a necessidade de separar-se a Justiça da Administração e de reconhecer-se uma jurisdição autônoma e independente como imperativo de justiça. A expressão Rechsstaat fez fortuna no âmbito da ciência política para designar um tipo de Estado qualificado por seus fins morais, contraposto ao Estado patriarcal, despótico, etc.: Estado de Direito é aquele que visa à realização e a manutenção do direito e da ordem legal.

Dado que, desde a revolução, o contencioso dos direitos fundamentais e o controle material de constitucionalidade é feito, na França, pela Jurisdição Administrativa, e que o Conselho Constitucional (criado em 1958) somente declara previamente a constitucionalidade das leis, coube ao Conselho de Estado dar um contorno preciso

\footnotetext{
${ }^{17}$ Decisão Benjamin, de 19 de maio de 1933. Les Grands Arrêts.., cit. pp. 300/306.

${ }^{18}$ Decisão Bouvet de la Maisonneuve et Millet, de 4 de junho de 1975, apud LONG et. al. Les Grands Arrêts, cit., p. 776.
} 
ao princípio da proteção à dignidade humana porque o afirmou como um componente da ordem pública, que o poder de polícia administrativa tem o dever de assegurar.

O passo decisivo foi dado quando à noção tradicional de ordem pública, que pertence ao Direito Administrativo, acrescentou-se a questão da ordem moral. Com isso, a noção tradicional, fundada sobre os elementos segurança, tranquilidade e salubridade foi alargada para compreender a proteção da dignidade humana. Por isso, o acórdão Morsang-Sur-Orge tem, no direito francês, o mesmo valor do acórdão Mephisto, no direito alemão, porque, nas duas decisões, examinou-se a natureza, conteúdo e extensão da proteção à dignidade humana em um caso concreto, e não abstratamente.

O que é continuamente afirmado em todas as cortes européias que conhecem litígios que versam sobre Direitos Humanos, é a que a dignidade da pessoa é inviolável, porque está fundada sobre os direitos inerentes ao ser humano. As discussões sobre o princípio de proteção à dignidade humana envolvem questões ligadas ao início da vida, à vida mesma (integridade física, mínimo existencial, condições de prisão e acusação, especialmente de extradição, respeito à vida privada e proteção diante de novas tecnologias), ao fim da vida e aos efeitos post mortem. Há igualmente acordo no sentido de que a proteção à dignidade da pessoa atua na defesa contra a ação do Estado, nos direitos às prestações positivas do Estado (direitos sociais), além de produzir efeitos nas relações de direito privado. Na determinação do domínio de proteção do princípio, está a proibição de tratar as pessoas como simples objetos e a sua aplicação é sempre feita em combinação com outros direitos fundamentais.

Não havendo um domínio de aplicação abstrato, o que se afirma é que a a dignidade da pessoa humana é norma fundamental que inspira a interpretação e aplicação da Constituição e, por isso mesmo, é o “coração” do sistema dos valores constitucionais. Em síntese, a proteção à dignidada da pessoa humana traduz, no plano jurídico, um antigo preceito cristão: "Senhor, quando é que te vimos com fome ou com sede, forasteiro ou nu, doente ou preso e não te servimos?E ele responderá com estas palavras: Em verdade vos digo: todas as vezes que o deixaste de fazer a um desses pequeninos, foi a mim que o deixaste de fazer.” (MATEUS, 25, 44-45).

\section{REFERÊNCIAS}

A Bíblia de Jerusalém. São Paulo: Edições Paulinas, 1985, p. 1887.

BARZOTTO, Luís Fernado, in: Justiça Social - Gênese, estrutura e aplicação de um conceito. Revista da Procuradoria-Geral do Município de Porto Alegre, ano 2003, volume 17.

GENEVOIS, Bruno. Les principes Généraux du Droit. Aspects de Droit Administratif. Revue Internationale de droit comparée. N. spécial - vol. 2. Journées de la Société de législation comparée. Année 1980. Paris: C.N.R.S., 1980.

HARDY, Jacques. Le Statut Doctrinal de La Juridprudence en Droit Administratif Français. Revue du Droit Public et la Science Politique en France et a l'Étranger. Paris: L.G.D.J., 1990, p. 455.

HAURIOU, Maurice. Précis de droit Administrafi et de droit public. 12e Édition. Revue et mise à jour par André Haurion. Réédition présentée par Pierre Devolvé et Frank Moderne. Paris: Dalloz, 2002.

KANT, I. La Metafísica de las Costumbres. 3a. Ed. Madrid: Editorial Tecnos, 1999. Tradução espanhola de Metaphysik des Sitten, por Adela Cortina Orts e Jesus Conill Sancho. 
LONG, WEIL, BRAIBANT, DEVOLVÈ e GENEVOIS. Les grands arrêts de la jurisprudence administrative. $13^{\mathrm{a}}$ édition. Paris: Dalloz, 2001.

ODENT, R. Contentieux administratif, 1980, p. 1708.

ROBERT, Jacques, OBERDORFF, Henri. Libertés fondamentales et droits de l'homme. $2^{\mathrm{a}}$. Édition. Paris: Montchrestien, 1995.

ROBERT, Jacques. Le principe de dignité de personne humaine. Venice Comission. Le principe du respec da la dignité de la personne. Montpellier, 2-6 juillet 1998. Actes du Séminaire UniDem organisé à Montpellier, France. Disponível in: www.venice.coe.int. Acesso em: 11 jun. 2005.

ROUVILLOIS, Frédéric. Le raisonnement finaliste do juge administratif. Revue du Droit Public et la Science Politique en France et a l'Étranger. Paris: L.G.D .J., 1990. 